\title{
Spatial Distribution and Time Series Analysis of COVID-19 Pandemic in Italy: A Geospatial Perspective
}

Muhammad Farhan UI Moazzam ( $\square$ farhan.moazzam@gmail.com )

Jeju National University https://orcid.org/0000-0002-5201-9649

Tamkeen Urooj Paracha

Hamdard University

Ghani Rahman

University of Gujrat

Byung Gul Lee

Jeju National University

Nasir Farid

University of Peshawar

Adnan Arshad

China Agricultural University

Research

Keywords: COVID-19, Public health, Geospatial analysis, IDW, Italy

Posted Date: September 15th, 2020

DOl: https://doi.org/10.21203/rs.3.rs-73628/v1

License: (1) This work is licensed under a Creative Commons Attribution 4.0 International License.

Read Full License 


\section{Abstract}

The novel coronavirus pandemic disease (COVID-19) affected the whole globe, though there is lack of clinical studies and its epidemiological features. But as per the observation, it has been seen that most of COVID-19 infected patients show mild to moderate symptoms and they get better without any medical assistance due to better immune system to generate antibodies against the novel coronavirus. In this study the active cases, serious cases, recovered cases, deaths and total confirmed cases have been analyzed using geospatial technique (IDW) with the time span of $2^{\text {nd }}$ March to $3^{\text {rd }}$ June 2020. As on $3^{\text {rd }}$ June the total number of COVID-19 cases in Italy were 231,238 , total deaths 33,310 , serious cases 350 , recovered cases 158,951 and active cases were 39,177 which has been reported by the Ministry of health, Italy. March $2^{\text {nd }}-$ June $3^{\text {rd }} 2020$ a sum of 231,238 cases has been reported in Italy out of which $38.68 \%$ cases reported in Lombardia region with death rate of $18 \%$ which is high from its national mortality rate followed by Emilia-Romagna (14.89\% deaths), Piemonte (12.68\% deaths), and Vento ( $10 \%$ deaths). As per the total cases in the region, the highest number of recoveries has been observed in Umbria (92.52\%), followed by Basilicata (87\%), Valle d'Aosta (86.85\%) and Trento (84.54\%).

The COVID-19 evolution in Italy has been particularly found in the major urban area i.e. Rome, Milan, Naples, Bologna and Florence. Geospatial technology played a vital role in this pandemic by tracking infected patient, active cases, and the recovered cases. Thus, monitoring and planning using geospatial technique is very important to control COVID-19 spread in the country.

\section{Introduction}

Pandemic wave of a deadly B-coronavirus (CoV) presenting with cases of extreme pneumonia originated from Wuhan, China in December, 2019. It was initially referred as novel corona virus (2019-nCoV) by WHO and also labelled as corona virus disease 2019 (COVID-19) [1-5]. International Committee on Taxonomy of Viruses (ICTV) termed it the SARS-CoV-2 virus based on its similarity to sever acute respiratory syndrome corona virus (SARS-CoV) [5]. In Italy, from 29th January till 16th June 2020, there have been 238,720 confirmed cases of COVID-19 with 34,345 deaths [6]. Not only Italy, corona virus has affected the whole world grossly with confirmation of around 8,061,550 cases of COVID-19, including 440,290 deaths, reported to WHO [7]. Even though Chinese researchers were able to provide SARS-CoV-2 genome sequence [8] but continuous human to human transmission of this contagious virus has produced devastating effects not only on human health sector but has dropped down world's economy to a high extent [9]. The potential of these corona viruses predisposing public health risk are quite higher and detrimental $[10,11]$. Albeit, fatality rate of COVID-19 infected persons in the Italian population, based on data up to March 17, was estimated as $7.2 \%$ [12]. This rate is comparatively higher in other regions of the world based on numerous factors such as testing strategies and population age [13] etc. Increased mortality burden implies utilization of strategies and policies by the Governments worldwide limiting the spread and transmission of this contagious virus via social distancing and other possible means such as use of personal protective equipments, face masks and use of sanitizers etc. [14]. 
Various clinical manifestations have been shown by COVID-19 including mild to moderate symptoms carriers along with asymptomatic infected carriers as majority to individuals with serious decline in lung function and death $[15,16]$. However, increase in mortality rate has been of relevance to individuals with pre-disposed respiratory malfunctioning, prior asthma, any lung disorder or decreased immunity. Serious illness caused by COVID-19 has been clinical dealt with use of mechanical support of ventilators and maintenance of oxygen saturation level [17], [18]. With the advent of latest reports and data, there have been researches enlisting features, disease transmission, its incubation and management protocols [10, 19]. A number of test trials are on-going based on their effectiveness to treat clinical manifestations of COVID-19, since there is no definite treatment or vaccine available to date. These clinical trials and scientific investigations regarding treatment include in-vitro chloroquine (old anti-malarial agent) [20], hydroxy chloroquine (quinine analogue) [21], azithromycin [22], remdesivir (anti-viral drug) [17] and dexamethasone for hyper inflammation in severe cases.

Many researchers have employed various techniques and strategies to address the spread of SARS pandemics $[23,24]$. Keeping various variable such as availability of appropriate health care systems, measurements to keep up the pace with patients' needs such as isolation practices and continuously emerging spread has led to a number of research studies in this regard. In addition to all variables, spatial distribution analysis and explicit geographic models are needed to predict and estimate the time series analysis of COVID-19 pandemic. Hence, geographical information system (GIS), thematic and spatial mapping are the emerging tools and are widely used throughout the world [25]. This study will provide a platform for researchers to conduct studies on COVID-19 with scope of GIS and mapping approach. Geospatial tools can be of essential use for knowledge, treatment, trend, and mitigation of the particular disease. The use of geospatial approach can give the visual glimpse of disease spread geographically, risk factors, and potential health facilities available for treatment. Therefore, these tools/methods can relate to the designing, planning, and the distribution of international health aid for treatment and prevention services [26]. The objective of this study is provide the spatial distribution of COVID-19, its trend and time series analysis of the disease using geospatial approach in Italy.

\section{Study area}

Italy is located in South-Central Europe but also considered in a western Europe, its capital is Rome. The total geographical area of Italy is $301,340 \mathrm{Km}^{2}$. It shares the border with France, Switzerland, Austria, and Slovenia. Italy consisting of a peninsula delimited by Alps mountains and surrounded by various islands. Italy is third most populous country in the European Union member states. The major cities in Italy are Rome, Milan, Naples, Bologna, Florence, Turin, and Genoa. According to 2019 the total population of Italy is $60,317,116$ with population density of 200.16 people/Sq.km (Figure 1). The most populous region in Italy is Lombardia and the least populous is Valle d'Aosta (Table 1).

The overall representation of COVID-19 variables in Italy shown below in Fig. 2. Total 231,238 cases of coronavirus have been reported from the last week of January to first week of June 2020. It is worth to 
mention that out of total 231,238 cases, $72.14 \%$ cases completely recovered but unfortunately $14.45 \%$ of people lost their lives while fighting against coronavirus and $13.40 \%$ cases are still active (Fig. 2).

Table 1

Region-wise Population of Italy (As of January, 2019)

\begin{tabular}{|llll|}
\hline Region & Population & Area $\left(\mathrm{Km}^{2}\right)$ & People/Sq.Km \\
\hline Abruzzo & $1,311,580$ & 10,763 & 121.86 \\
\hline Apulia & $4,029,053$ & 19,385 & 207.84 \\
\hline Basilicata & 562,869 & 9,995 & 56.31 \\
\hline Calabria & $1,947,131$ & 15080 & 129.12 \\
\hline Campania & $5,801,692$ & 13,590 & 426.90 \\
\hline Emilia-Romagna & $4,459,477$ & 22,446 & 198.67 \\
\hline Friuli-Venezia Giulia & $1,215,220$ & 7,858 & 154.64 \\
\hline Lazio & $5,879,082$ & 17,236 & 341.09 \\
\hline Liguria & $1,550,640$ & 5,442 & 284.93 \\
\hline Lombardia & $10,060,574$ & 23,884 & 421.22 \\
\hline Marche & $1,525,271$ & 9,366 & 162.85 \\
\hline Molise & 305,617 & 4,438 & 68.86 \\
\hline Piemonte & $4,356,406$ & 25,402 & 171.49 \\
\hline Sardegna & $1,639,591$ & 24,090 & 68.06 \\
\hline Sicily & $4,999,891$ & 25,711 & 194.46 \\
\hline Toscana & $3,729,641$ & 22,993 & 162.20 \\
\hline Trentino-Alto Adige & $1,072,276$ & 13,607 & 78.80 \\
\hline Umbria & 882,015 & 8,456 & 104.30 \\
\hline Valle d'Aosta & 125,666 & 3,263 & 38.51 \\
\hline Veneto & $4,905,854$ & 18,399 & 266.63 \\
\hline Source: [27] & & & \\
\hline
\end{tabular}

\section{Material And Methods}

The COVID-19 data for Italy was obtained from various sources [28-30]. The data of this study is the number of COVID-19 confirmed cases, deaths, serious patients, active patients and recoveries from this 
disease region-wise in Italy from early March 2020 to $3^{\text {rd }}$ June, 2020. In the present study, to show the pattern of disease transmission and forecasts the number of patients using GIS tool, the interpolation technique used i.e. Inverse Distance Weighted (IDW).

\section{Interpolation IDW}

IDW is based on the concept of Tobler's first law (the first law of geography) from 1970. It was defined as everything is related to everything else, but near things are more related than distant things. The IDW was developed by the U.S. National Weather Service in 1972 and is classified as a deterministic method. This is due to the lack of requirement in the calculation to meet specific statistical assumptions, thus IDW is different from stochastic methods (e.g., Kriging and TRA) [31].

Spatial interpolation (IDW) is the method based on the function of inverse distances in which weight increases as the distance decreases and vice versa. It means that the points with known values used to estimate values of unknown points. The necessities of known points discriminates spatial interpolation from isopleth mapping, which uses allocated points such as polygon centroids for interpolation. A basic theory in spatial interpolation is that the value to be assessed at a point is more influenced by near known points than those are farther away. The assumption of a random process is usually mandatory for a stochastic method. Inverse Distance weighted (IDW) interpolation is an exact method that estimates the value of a point that is influenced by nearby known points than those farther away. The general equation of IDW method is:

$$
\mathrm{K}_{\mathrm{xy}}=\frac{\sum_{i=1}^{N} \mathrm{~K}_{\mathrm{i}} \mathrm{W}_{\mathrm{i}}}{\sum_{i=1}^{N} \mathrm{w}_{\mathrm{i}}}
$$

Where, $\mathrm{K}_{\mathrm{i}}$ is the control value for Ith sample point, $\mathrm{W}_{\mathrm{i}}$ represents a weight determining the relative importance of individual control point $\mathrm{K}_{\mathrm{i}}$ in the interpolation process, $\mathrm{K}_{\mathrm{xy}}$ is the point to be estimated and $\mathrm{N}$ is the number of sample points [32].

\section{Results}

The novel corona virus is well spread all over the country. There are total 231,238 cases reported from $2^{\text {nd }}$ March to $3^{\text {rd }}$ June 2020 (Table 2). In this study, the region wise data was collected and linked it with point data. The 20 region's data of Italy has been analyzed to find out the variability. The IDW technique was used to show the current status and magnitude of the infection disease spread (COVID-19) in Italy using ArcGIS 10.5 .

Table 2 Region wise breakdown of COVID-19 Statistics in Italy 


\begin{tabular}{|c|c|c|c|c|c|}
\hline Region & $\begin{array}{l}\text { Confirmed } \\
\text { Cases }\end{array}$ & $\begin{array}{l}\text { Confirmed } \\
\text { Deaths }\end{array}$ & $\begin{array}{l}\text { Serious } \\
\text { Patients }\end{array}$ & $\begin{array}{l}\text { Recovered } \\
\text { Patients }\end{array}$ & $\begin{array}{l}\text { Active } \\
\text { Cases }\end{array}$ \\
\hline Abruzzo & 3252 & 414 & 3 & 2102 & 736 \\
\hline Apulia & 4499 & 511 & 10 & 2952 & 1036 \\
\hline Basilicata & 399 & 27 & 0 & 349 & 23 \\
\hline Calabria & 1158 & 97 & 0 & 951 & 110 \\
\hline Campania & 4821 & 415 & 4 & 3737 & 869 \\
\hline $\begin{array}{l}\text { Emilia- } \\
\text { Romagna }\end{array}$ & 27842 & 4147 & 50 & 20856 & 2839 \\
\hline $\begin{array}{l}\text { Friuli-Venezia } \\
\text { Giulia }\end{array}$ & 3276 & 336 & 2 & 2707 & 233 \\
\hline Lazio & 7753 & 747 & 51 & 4188 & 2818 \\
\hline Liguria & 9751 & 1473 & 6 & 7764 & 514 \\
\hline Lombardia & 89442 & 16172 & 131 & 53046 & 20224 \\
\hline Marche & 6735 & 987 & 8 & 4438 & 1310 \\
\hline Molise & 436 & 22 & 2 & 287 & 127 \\
\hline Piemonte & 30734 & 3898 & 44 & 22150 & 4686 \\
\hline Sardegna & 1357 & 131 & 1 & 1080 & 146 \\
\hline Sicily & 3447 & 275 & 7 & 2292 & 880 \\
\hline Toscana & 10121 & 1055 & 25 & 8093 & 973 \\
\hline Trento & 4433 & 463 & 2 & 3748 & 222 \\
\hline Umbria & 1431 & 76 & 2 & 1324 & 31 \\
\hline Valle d'Aosta & 1187 & 143 & 0 & 1031 & 13 \\
\hline Veneto & 19164 & 1921 & 2 & 15856 & 1387 \\
\hline Total & 231,238 & 33,310 & 350 & 158,951 & 39,177 \\
\hline
\end{tabular}

*Ministry of Health, Italy (3 ${ }^{\text {rd }}$ June, 2020)

Interpolation using IDW has been applied with the of purpose of predicting the spread of the coronavirus in Italy. As of June 3, 2020 in Italy a total of 39,177 active cases of coronavirus has been reported. The map obtained from interpolation of active cases as per $3^{\text {rd }}$ June, 2020 which was divided into eight classes using natural break classification method. The pattern of classes is 14 to 1044,1045 to 2332 , 2333 to 3738,3739 to 5877,5878 to 8888,8889 to 12295,12296 to 15940,15941 to 20219 as shown in 
Figure 3. The various regions of Italy are at risk based on population density. More than $50 \%$ of active cases were found in northern Italy particularly in the region of Lombardia due to the most populous region of the Italy. It can be observed from Figure 3a that Piemonte region has the second highest active cases with 4686 out of total 39,177 as of $3^{\text {rd }}$ June, 2020. Emilia-Romagna and Lazio regions with $7.25 \%$ and $7.19 \%$ of active cases respectively. In order to understand the influence of population density, a Pearson correlation co-efficient was performed using COVID-19 data. There was a positive correlation seen in number of active cases of COVID-19 and population density [where $r(18)=0.323)$ ] (Table 3). [(See appendix Figure S/ 3(a)].

In Figure $3 \mathrm{~b}$ the spatial distribution of serious cases has been showed. It can be observed that most dense region (Campania) has only 4 serious cases as per June $3^{\text {rd }}, 2020$ out of total 350 serious cases. The highest number of serious cases has been taken place in Lombardia 131 (37.42\%) followed by Lazio, Emilia-Romagna and Piemonte. Data presented in Table 3 shows the positive association between serious coronavirus cases and population density [where $r(18)=0.340)$ ]. [(See appendix Figure $S / 3(b)]$.

Total 33,310 deaths have been reported officially as of $3^{\text {rd }}$ June, 2020. According to ministry of health, the Lombardia region alone reported 16,172 deaths due to coronavirus which have a population density of 421 person/Sq.Km. Nearly 4147 (12.45\%), 3898 (11.70\%) and 1921 deaths have been reported in the region of Emilia-Romagna, Piemonte, and Vento respectively. Following Table 3 clearly depicts the relationship between total deaths caused by COVID-19 and population density [where $r(18)=0.292)$ ]. [(See appendix Figure SI 3(c)].

Total 158,951 patients recovered from coronavirus infection in Italy as of $3^{\text {rd }}$ June, 2020 which is $69 \%$ of total confirmed coronavirus cases. Lombardia region has observed a spike in the number of recovered patients from coronavirus. the region has alone 89442 people infected out of which 53046 recovered. The Lombardia region has $60 \%$ recovery rate which is highest in Italy but is below the national average of 69 percent and also contribute 33 percent of the total recoveries nationwide. Piemonte, Emilia-Romagna, and Vento infected 30734, 27842 and 19164 people respectively out of which 22150, 20856, and 15856 people recovered completely. Table 3 indicated a positive correlation between population density and total recovered cases from coronavirus [where $r(18)=0.313)]$. [(See appendix Figure S/ 3(d)].

After Wuhan, China, the Italy was the next hotspot of infectious disease of coronavirus. The first corona positive case was detected in Italy on $31^{\text {st }}$ of January,2020 when two Chinese tourist visited Rome [33] and a week later an Italian man returned from china reported positive [34]. Later a cluster of positive cases detected in the region of Lombardia $[35,36]$ and then in the first half of March the virus spread all over the country [37]. The COVID-19 infections disease caused major health burden and emergency situation across the Italy. Total COVID-19 cases in Italy were 231,238 as of $3^{\text {rd }}$ June, 2020. It can be observed from Figure 5 below that Lombardia has the highest number of confirmed cases (89442) which has kept the government on its toes due to sharp surge in the number of coronavirus cases. Piemonte, Emilia-Romagna and Toscana followed Lombardia with $13.29 \% 12.04 \%$ and $4.38 \%$ cases respectively. The huge number of COVID-19 cases was a threat to the citizen of Italy and its economy. A correlation is 
found between number of COVID-19 cases and the population of various regions of Italy [where $\mathrm{r}(18)=$ 0.318)] (Table 3). To understand the correlation, a scatterplot is shown for better representation [(See appendix Figure SI 3(e)].

Below in Figure 6, a dashboard has been made in individual capacity only for this study. Dashboard is the collection of several views, letting you to compare the variety of the data at the same-time. It is best to display a set of information on dashboard rather than navigating for the information separately. In this dashboard one can see the number of active cases, serious cases, recovered cases, deaths and total cases, along with an interactive map in the middle of dashboard. The regional level information is also shown on left side in the dashboard. On the right hand side of the map, the national trend on coronavirus can also be observed.

Table 3 Association between population density and COVID-19 variables using Pearson correlation

\begin{tabular}{|lllll|}
\hline Variables & Test Statistics $(\mathrm{t})$ & Degree of freedom $(\mathrm{df})$ & P value & Correlation Co-efficient \\
\hline Active Cases & 2.929 & 18 & 0.009 & 0.323 \\
\hline Serious Cases & 3.043 & 18 & 0.007 & 0.340 \\
\hline Total Deaths & 2.727 & 18 & 0.014 & 0.292 \\
\hline Recovered Cases & 2.867 & 18 & 0.010 & 0.313 \\
\hline Confirmed Cases & 2.898 & 18 & 0.010 & 0.318 \\
\hline
\end{tabular}

\section{Discussion}

The COVID-19 infection disease have triggered major health burden all over the country. As of 3rd June, 2020 total of 231, 238 cases have been report in Italy. It has found that Lombardia region has the highest number of cases followed by Piemonte, Emilia-Romagna, and Vento. Basilicata has the lowest number of cases but Lombardia has the highest rate of death for coronavirus disease. The mortality rate of Lombardia is very high comparatively to nationwide. In Molise only 22 people lost their life; moreover, Basilicata is another coronavirus fighter with total 399 cases and 27 deaths reported. Doctors and paramedic staff is playing a very crucial role in COVID-19 pandemic by treating the infected cases. There is a high recovery rate and a low death rate in Italy which indicates the better medical facilities with a suitable doctor and patient ratio.

The human health being affected from COVID-19 but on the other hand lockdown affected the Italy's economy as multiple factories are closed due to the nationwide emergency situation. The accommodation and food services were the hardest hit due to emergency situation and ban on tourism. The economist predicted 7\% GDP decline for the year of 2020 [38]. Northern Italy was hardest hit by coronavirus but the economically deprived parts of southern Italy suffered the most from lockdown $\backslash n$ [39]. 


\section{Conclusion}

This research work was carried out using geospatial technology to show the spatial distribution of coronavirus disease in Italy. The objective of this research work was to evaluate the temporal change in the rate of COVID-19 across the country by performing analysis from March to June 2020 (See Appendix). It is worth to mention that the strict steps taken to control the spread of coronavirus disease, within this twelve-week sampling data, the daily cases and daily deaths has been reduced from mid of April and there is a spike in number of daily recovered cases (See Appendix).

This study was conducted for Italy on disease that have spread globally, thus the pattern of its spatial distribution was studied using geospatial approach. Time series analysis was also conducted on the pattern of daily confirmed cases, and deaths. The study revealed that the most populous region of Italy (Lombardia) highly suffered from corona virus with $38 \%$ of total cases and $18 \%$ of total deaths (Table 2 ).

Analysis of spatial distribution pattern may offer valued information to support government monitoring and the envisaging extent of the virus through small and large areas. Thus, in this study a GIS-based spatial interpolation (IDW) approach was used to identify the prospective disease risk areas in Italy. The IDW analysis of the spatial interpolation layers and the apparent weight of the conditioning factors were also prepared.

The findings of this study would be appropriate for the relevant departments to carry out the detailed study on spread of corona virus and environmental control in the study area. Moreover, the approach does not merely proscribe the foretell mapping of various zones of the country, but also allow the demonstration of the level of improbability in the forecast that could be appropriate for other countries.

\section{Recommendation For Covid-19}

In view of the findings related to the circumstances of dominance and spread of COVID-19, the following suggestions have been protracted, which if employed, may go a long way in controlling the spread of the highly contagious disease:

- Execution of the guidelines of WHO and COVID-19 control programs at national level.

- Formation of the COVID-19 research center must be taken up on an urgency basis.

- The government should upsurge the budget for the health facilities.

- Hospitals should be distributed according to population and vulnerability of areas.

- Private clinics should refer the patients showing symptoms of infection to hospitals for complete diagnosis.

- Awareness among patients about the disease and its precautionary and curative processes must be promoted.

- Symptoms and cautionary methods about the disease should be ensured through signboards, print and electronic media. 
- Improvement of quality of life is a principal factor among all factors, which is essential to be enhanced by making proper reforms in the economy of the country.

\section{Declarations}

Data Availability. All data used in this manuscript are publicly available. COVID-19 epidemiological data for Italy are available at https://github.com/pcm-dpc/COVID-19. Administrative boundaries area available at http://www.diva-gis.org/gdata. Population census data are available at http://dati.istat.it/Index.aspx? Queryld $=18460$. National level COVID-19 daily updated data is available at https://ourworldindata.org/coronavirus

Funding. This research was a part of the project titled 'Jeju Sea Grant' funded by the Ministry of Oceans and Fisheries, South Korea.

Conflict of interest. The authors declare no conflict of interest.

\section{References}

1. Wang, D., et al., Clinical characteristics of 138 hospitalized patients with 2019 novel coronavirusinfected pneumonia in Wuhan, China. Jama, 2020. 323(11): p. 1061-1069.

2. Lu, H., C.W. Stratton, and Y.W. Tang, Outbreak of Pneumonia of Unknown Etiology in Wuhan China: the Mystery and the Miracle. Journal of Medical Virology.

3. Huang, C., et al., Clinical features of patients infected with 2019 novel coronavirus in Wuhan, China. The lancet, 2020. 395(10223): p. 497-506.

4. World Health, O., World Health Organization best practices for the naming of new human infectious diseases. 2015, World Health Organization: Geneva.

5. Coronaviridae Study Group of the International Committee on Taxonomy of, V., The species Severe acute respiratory syndrome-related coronavirus: classifying 2019-nCoV and naming it SARS-CoV-2. Nature microbiology, 2020. 5(4): p. 536-544.

6. WHO. World Health Emergency Dashboard. 2020; Available from: https://covid19.who.int/region/euro/country/it.

7. WHO. WHO Coronavirus Disease (COVID-19) Dashboard. 2020; Available from: https://covid19.who.int/.

8. Lu, R., et al., Genomic characterisation and epidemiology of 2019 novel coronavirus: implications for virus origins and receptor binding. The Lancet, 2020. 395(10224): p. 565-574.

9. Chan, J.F.-W., et al., A familial cluster of pneumonia associated with the 2019 novel coronavirus indicating person-to-person transmission: a study of a family cluster. The Lancet, 2020. 395(10223): p. 514-523.

10. Cascella, M., et al., Features, evaluation and treatment coronavirus (COVID-19), in Statpearls [internet]. 2020, StatPearls Publishing. 
11. Gao, G.F., From "A" IV to "Z" IKV: attacks from emerging and re-emerging pathogens. Cell, 2018. 172(6): p. 1157-1159.

12. Livingston, E. and K. Bucher, Coronavirus disease 2019 (COVID-19) in Italy. Jama, 2020. 323(14): p. 1335-1335.

13. Onder, G., G. Rezza, and S. Brusaferro, Case-fatality rate and characteristics of patients dying in relation to COVID-19 in Italy. Jama, 2020. 323(18): p. 1775-1776.

14. Dowd, J.B., et al., Demographic science aids in understanding the spread and fatality rates of COVID19. Proceedings of the National Academy of Sciences, 2020. 117(18): p. 9696-9698.

15. of the International, C.S.G., The species Severe acute respiratory syndrome-related coronavirus: classifying 2019-nCoV and naming it SARS-CoV-2. Nature Microbiology, 2020. 5(4): p. 536.

16. Wu, Z. and J.M. McGoogan, Characteristics of and important lessons from the coronavirus disease 2019 (COVID-19) outbreak in China: summary of a report of 72314 cases from the Chinese Center for Disease Control and Prevention. Jama, 2020. 323(13): p. 1239-1242.

17. Berlin, D.A., R.M. Gulick, and F.J. Martinez, Severe Covid-19. New England Journal of Medicine, 2020.

18. Marini, J.J. and L. Gattinoni, Management of COVID-19 respiratory distress. Jama, 2020.

19. Brochard, L., A. Slutsky, and A. Pesenti, Mechanical ventilation to minimize progression of lung injury in acute respiratory failure. American journal of respiratory and critical care medicine, 2017. 195(4): p. 438-442.

20. Gao, J., Z. Tian, and X. Yang, Breakthrough: Chloroquine phosphate has shown apparent efficacy in treatment of COVID-19 associated pneumonia in clinical studies. BioScience Trends, 2020. advpub.

21. Biot, C., et al., Design and synthesis of hydroxyferroquine derivatives with antimalarial and antiviral activities. Journal of medicinal chemistry, 2006. 49(9): p. 2845-2849.

22. Gautret, P., et al., Hydroxychloroquine and azithromycin as a treatment of COVID-19: results of an open-label non-randomized clinical trial. International journal of antimicrobial agents, 2020: p. 105949.

23. Gatto, M., et al., Spread and dynamics of the COVID-19 epidemic in Italy: Effects of emergency containment measures. Proceedings of the National Academy of Sciences, 2020. 117(19): p. 1048410491.

24. Center, C., Coronavirus COVID-19 Global Cases by the Center for Systems Science and Engineering (CSSE) at Johns Hopkins University. 2020.

25. Bergquist, R. and L. Rinaldi, Health research based on geospatial tools: a timely approach in a changing environment. Journal of helminthology, 2010. 84(1): p. 1-11.

26. Murugesan, B., et al., Distribution and Trend Analysis of COVID-19 in India: Geospatial Approach. J. Geographical Studies, 2020. 4(1): p. 1-9.

27. ISTAT, Population Italian regions. 2019.

28. MOH, PCM-DPC data by Ministry of Health. 2020, Ministero della Salute.

29. Outbreak, Hi This is Outbreak. 2020. 
30. ISS, Epidemia COVID-19. 2020, Istituto Superiore di Sanità: Italy.

31. Chen, F.-W. and C.-W. Liu, Estimation of the spatial rainfall distribution using inverse distance weighting (IDW) in the middle of Taiwan. Paddy and Water Environment, 2012. 10(3): p. 209-222.

32. Bartier, P.M. and C.P. Keller, Multivariate interpolation to incorporate thematic surface data using inverse distance weighting (IDW). Computers \& Geosciences, 1996. 22(7): p. 795-799.

33. Severgnin, C., Coronavirus: Primi due casi in Italia, in Corriere della sera 2020: Italy.

34. Anzolin, E. and A. Amante, First Italian dies of coronavirus as outbreak flares in north, in Reuters. 2020, Thomson Reuters.

35. Ravizza, S., Coronavirus: first cases in Milan. What do we know about the new infections in Lombardy, Veneto and Piedmont, in Corriere della Sera. 2020: Italy.

36. Elisa Anzolin, A.A., Coronavirus outbreak grows in northern Italy, 16 cases reported in one day, in Reuters. 2020, Thomson Reuters: Italy.

37. Editorial, I., Coronavirus. Hit all regions. Civil Protection: here are the updated numbers, in Avvenire. 2020: Italy.

38. Mafia primed to feast on Italy's virus devastation in France 24. 2020: Rome, Italy.

39. Nadeau, B.L. and V.D. Donato, As northern Italy is ravaged by coronavirus, there's trouble brewing down south, in CNN. 2020.

\section{Figures}




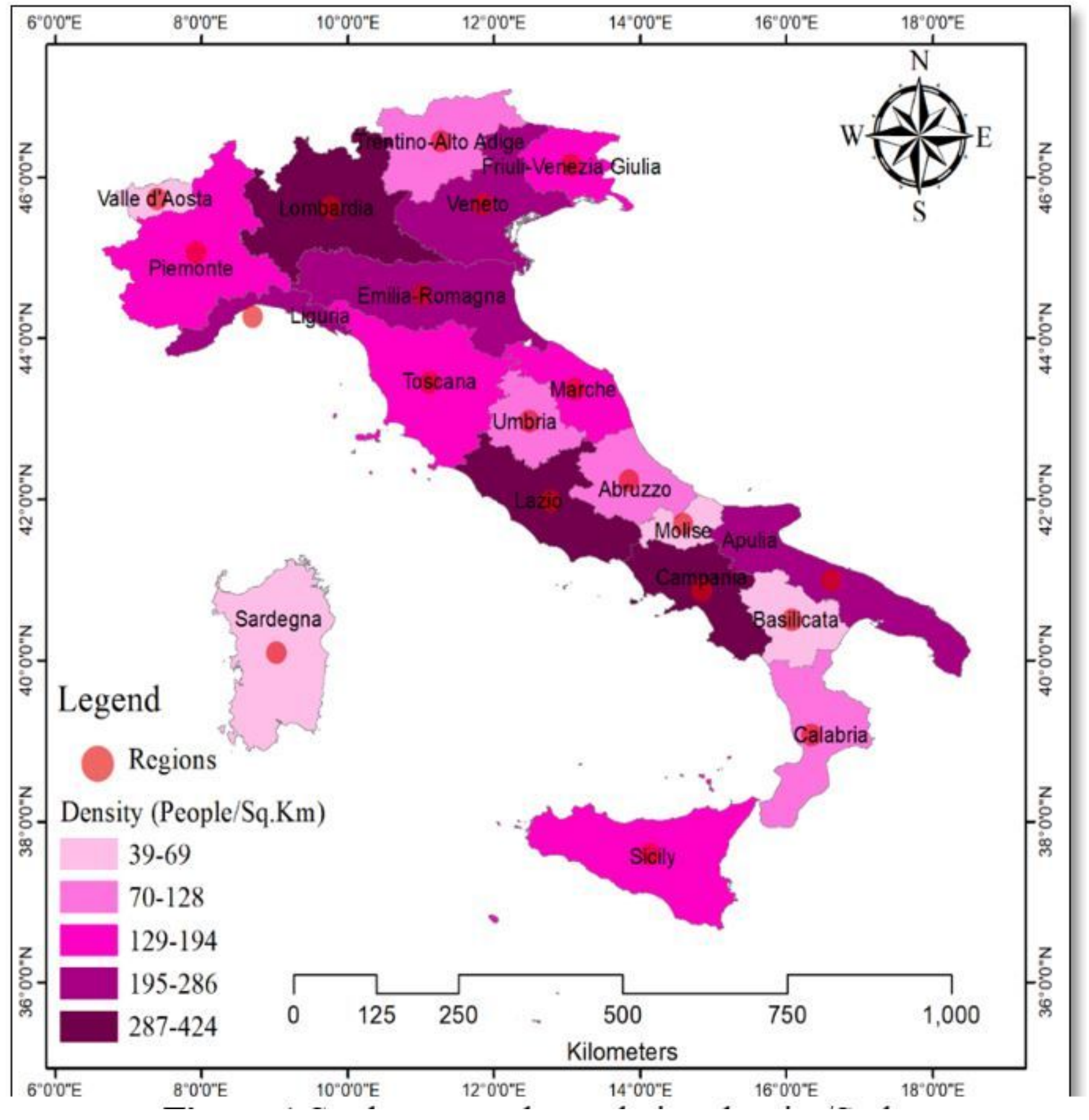

Figure 1

Study area and population density/Sq.km 


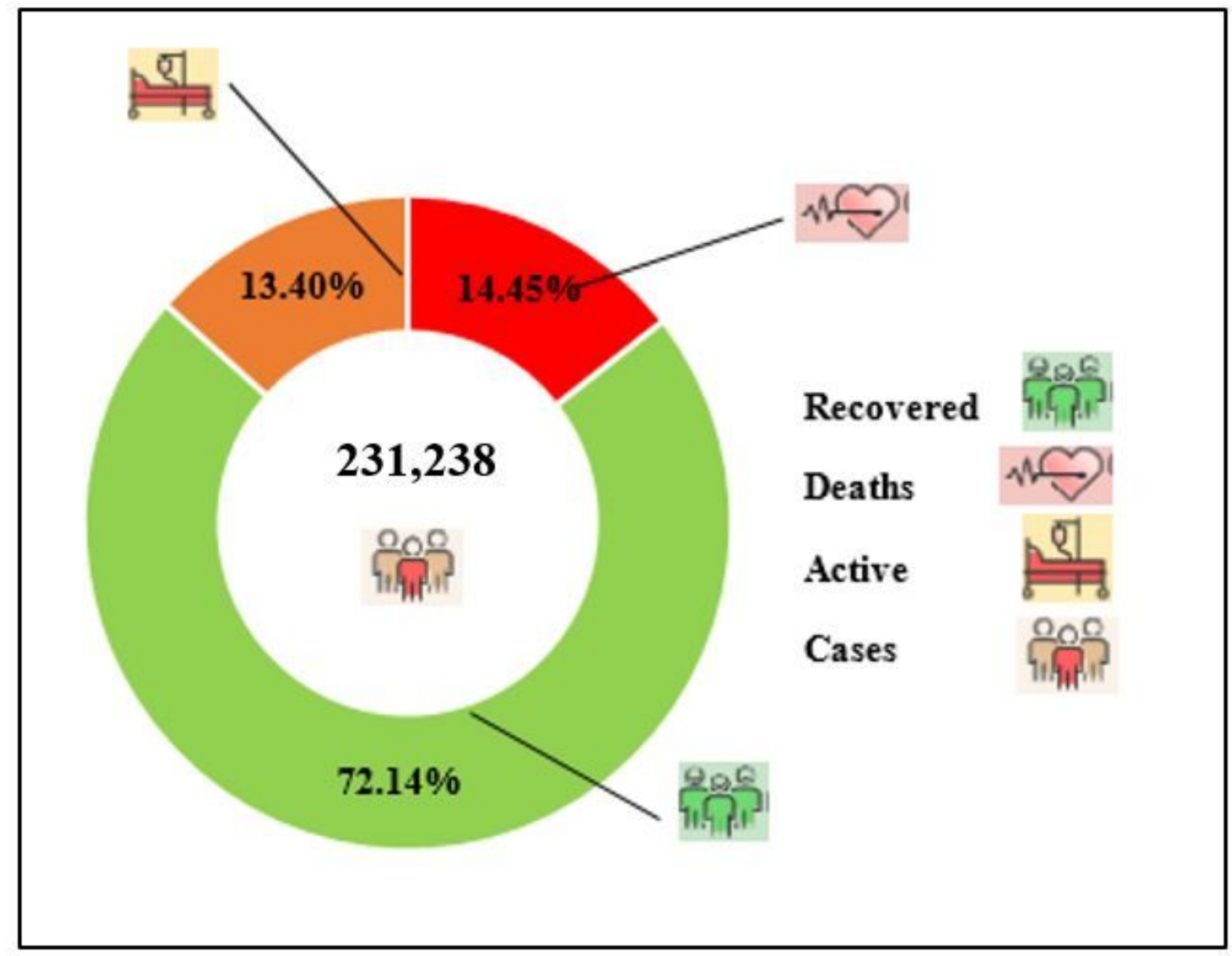

Figure 2

Statistics of COVID-19 in Italy (3rd June, 2020)
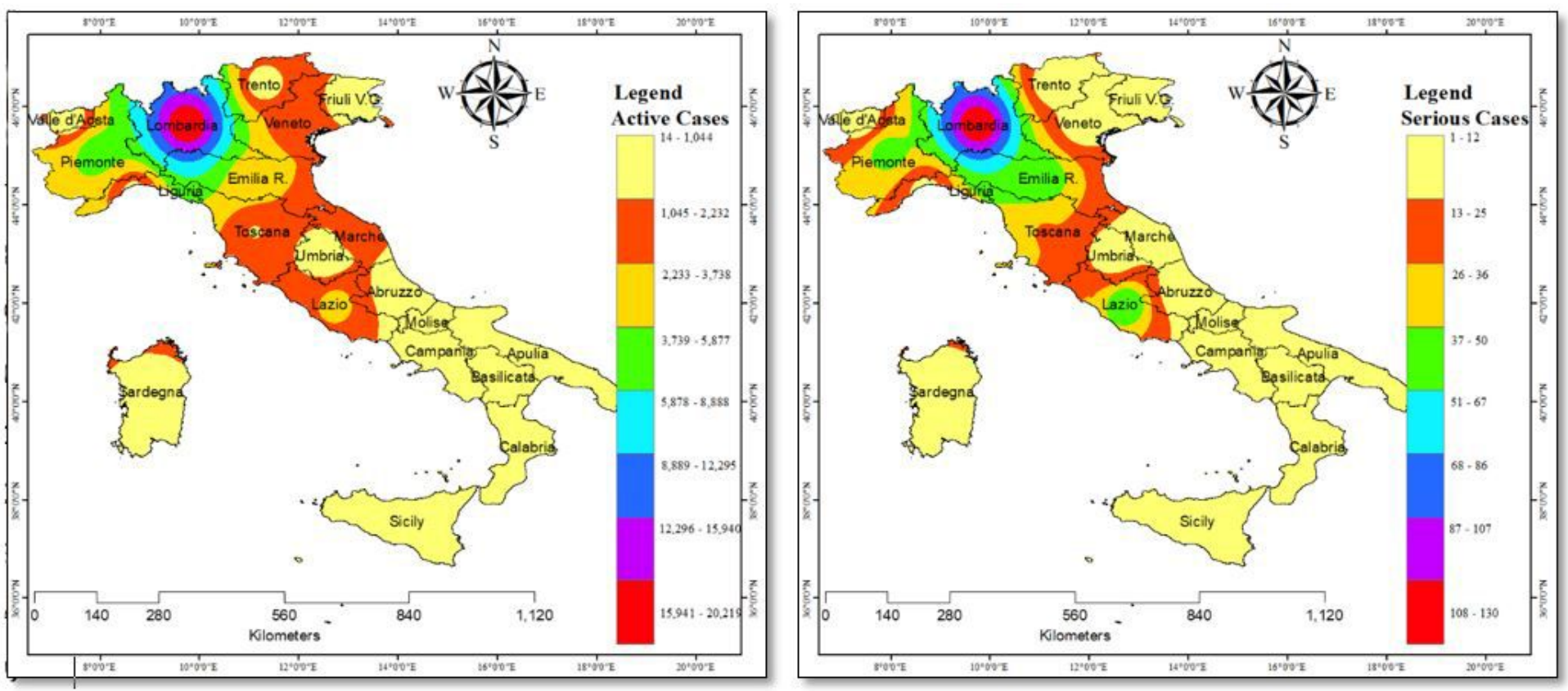
Figure 3

Spatial distribution of Coronavirus in Italy (a) Active cases (b) Serious cases
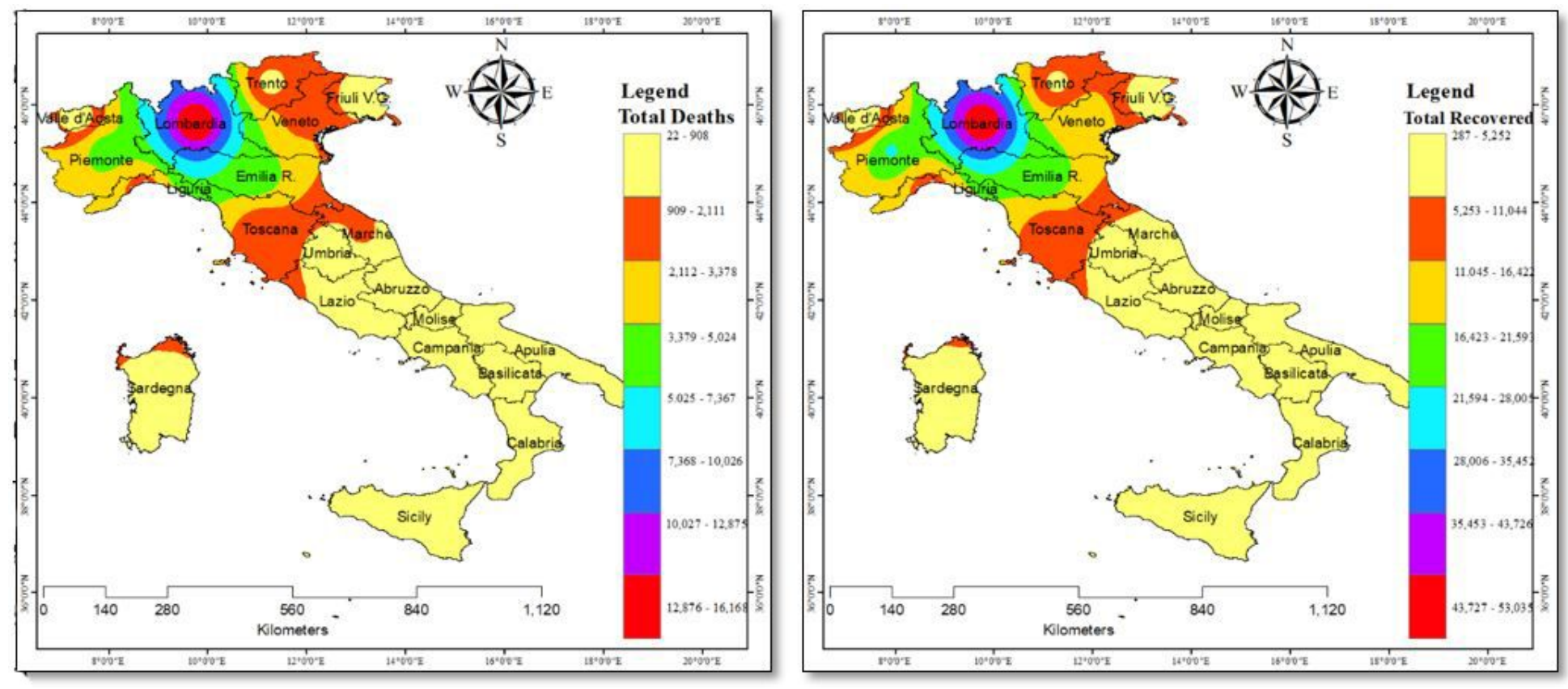

Figure 4

Spatial distribution of coronavirus in Italy (a) Total deaths (b) Total recovered 


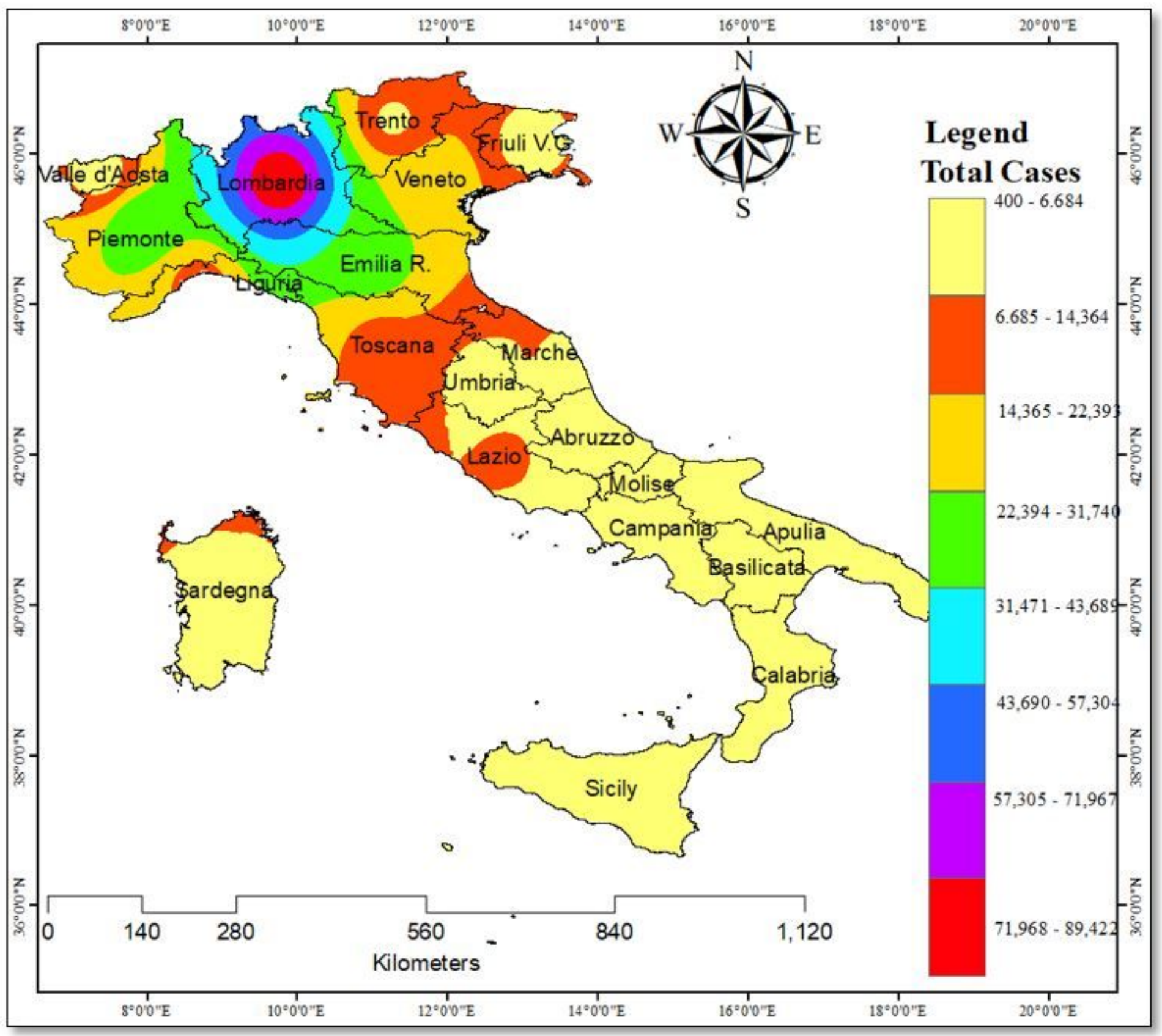

Figure 5

Spatial distribution of total Coronavirus cases in Italy 


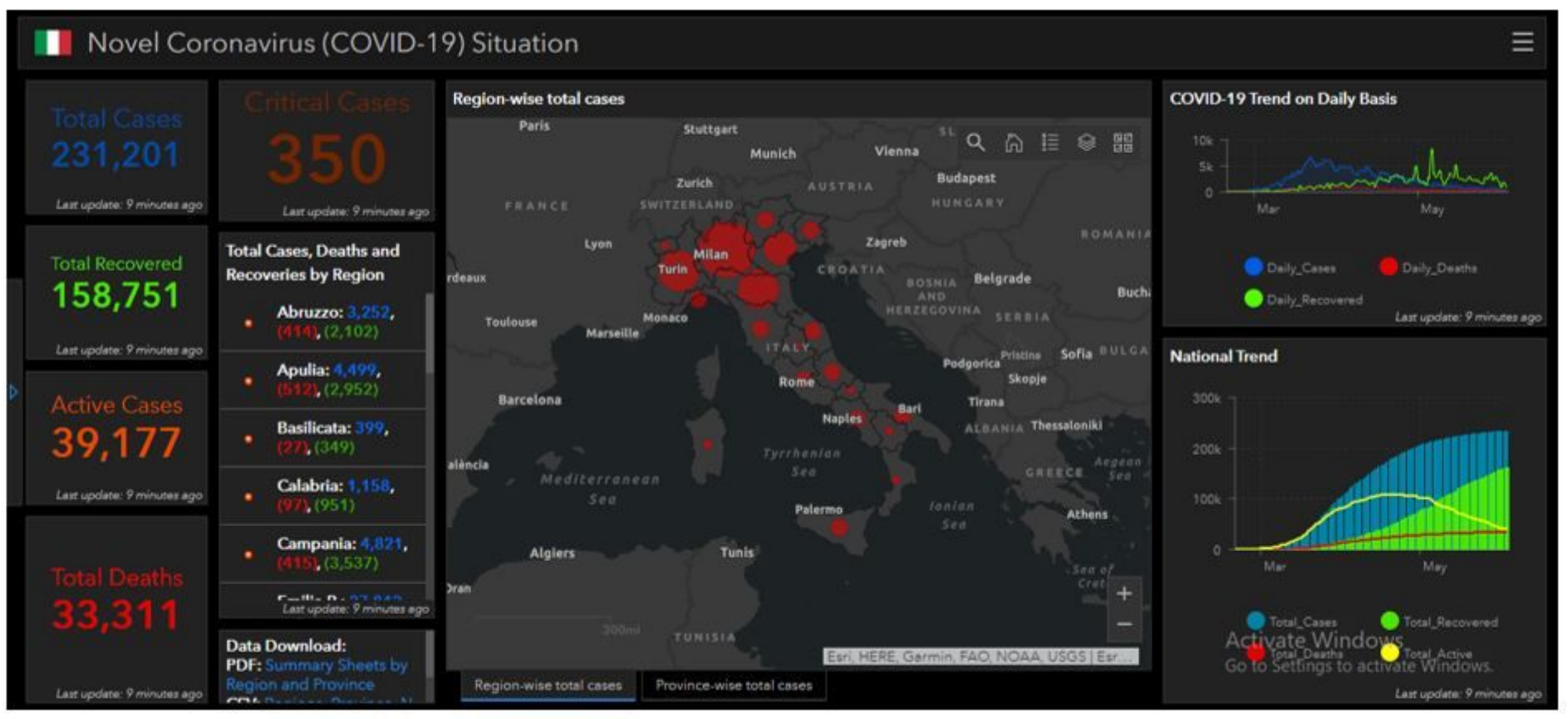

\section{Figure 6}

Dashboard for Novel Coronavirus (COVID-19) Situation in Italy Accessible Link: Novel Coronavirus (COVID-19) Situation in Italy

\section{Supplementary Files}

This is a list of supplementary files associated with this preprint. Click to download.

- Cases.mp4

- Cases.mp4

- Active.mp4

- Active.mp4

- Serious.mp4

- Serious.mp4

- Recover.mp4

- Recover.mp4

- Death.mp4

- Death.mp4

- AppendixltalyCOVID19.docx

- AppendixltalyCOVID19.docx 